\title{
Editorial
}

\section{Updating Ebbinghaus on the Science of Memory}

\author{
Eryn J. Newman ${ }^{\star a}$, Elizabeth F. Loftus ${ }^{b}$ \\ ${ }^{a}$ Victoria University of Wellington, Wellington, New Zealand. ' University of California, Irvine, USA.
}

Europe's Journal of Psychology, 2012, Vol. 8(2), 209-216, doi:10.5964/ejop.v8i2.453

Received: 2012-04-11. Published: 2012-05-31.

${ }^{*}$ Corresponding author at: Psychology \& Social Behavior, Criminology, Law \& Society, School of Social Ecology, University of California, Irvine, 2393

Social Ecology II, Irvine, Calif.92697-7080 USA, email:eloftus@uci.edu.

\footnotetext{
(c) (i) This is an open access article distributed under the terms of the Creative Commons Attribution License

(http://creativecommons.org/licenses/by/3.0), which permits unrestricted use, distribution, and reproduction in any medium, provided the original work is properly cited.
}

Of all the higher mental processes, memory ranks up there as one of the most crucial. It helps us do rudimentary tasks such as turning on the toaster in the morning, grinding our coffee and meeting a friend at the right time. But it also helps us do more sophisticated things too: like solving complex problems, feeling love, reminiscing with family and telling stories about our lives. Without memory, we wouldn't be able to do these things very well, if at all.

Psychological scientists have been studying memory experimentally for a mere 150 years or so, a much shorter time than has lapsed since the beginning of experimental work in some other sciences such as astronomy or physics. One of the early pioneers in the field of memory was Hermann Ebbinghaus, a German psychologist who is well known for his discovery of the forgetting curve after conducting experiments on himself using nonsense syllables. Although he died in 1909, his legacy lives on in introductory psychology lectures all over the world.

You can imagine our shock when one day we received a letter from Ebbinghaus asking us what had happened in the field of memory since his death over 100 years ago. We had so much to tell him, that we thought it would be more efficient to have a personal conversation. We located Ebbinghaus and managed to arrange a quick Skype conversation (Readers, please suspend for a few minutes your natural skepticism about our ability to Skype with those who have passed on).

\section{How we Study Memory these Days}

It seemed appropriate to talk about the matter of how many subjects one typically sees in a memory study, so this was the first issue on which we updated Ebbinghaus (who said we could call him Hermann). We told him that we run experiments not on ourselves but with groups of subjects, and sometimes the groups are quite large. In fact, one recent study involved over 2000 subjects whose memories of the events of September 11th were tested (Hirst et al., 2009). We added that subjects are often diverse; students of psychology and members of the public, young children, older adults and clinical populations including people suffering from depression and anxiety. "How 
do you find such diverse groups to study?" he asked. We explained that you can find them in train stations and shopping malls (we had to explain that one), and other public places. But a great new source is to find the subjects online. "Online?, is that in Europe?" he wondered. After explaining to him, the best we could, what the internet was all about, we told him about one of its big advantages; researchers don't even have to be in proximity of their research subjects in order to run studies; they can be sitting at their offices writing manuscripts and preparing teaching material and the study marches on. "That seems like a more efficient route to tenure" he quipped.

In our memory experiments today we ask people to study words or stories, watch events presented as movies, and even have actors pretend to steal things during an experiment so we can study people's memory for a crime. After they do these tasks we measure people's memory just like you did, by asking them to recall what they have learned. But we can also do more sophisticated things too like measure how long it takes people to remember information and examine people's eye movements while they watch an event to measure what information they attend to. We can also measure people's heartbeat, and skin conductance (how much their hands sweat) to tell us how distressed they are when recalling certain memories. Put simply, we have a sophisticated package of tools that are helping us to unravel the mysteries of human memory. "Wow" Hermann said, "What else can you measure?" We then explained that we can measure activity in the brain using electrodes that tell us when the brain responds to certain stimuli. "That is amazing." he gasped. But we also have tools that allow us to look inside the brain. He looked baffled. We further explained that we can look inside the brain using technologies that allow us to measure which areas in the brain are involved in performing a particular mental task. Using this technology, we now know that when people remember an event from the past, specific areas in the brain are recruited when we try to search for a memory, add details to it and relate the memory to ourselves (See Cabeza \& St. Jacques, 2007 for a review). "How fascinating. It sounds like science fiction" he said.

We told Hermann that this technology has also helped us understand what people use memory for. They use it, for example, when they imagine their future. Researchers have asked what happens in the brain when you imagine and insert yourself in future scenarios, like taking a vacation, graduating from university, or your wedding day. This research has told us that the act of imagining future events recruits similar brain regions to recalling past events (see Addis, Wong, \& Schacter, 2007; Szpunar, Watson, \& McDermott, 2007). Hermann wondered out loud, "...so does that mean in 2012 scientists think that imagining the future is the same as remembering?" Not quite, we told him. The idea is that people use memories from past events as the raw materials for future thinking, but they must go beyond just remembering past events (Suddendorf \& Corballis, 2007). They must reorganize and reconstruct past details to create a novel future scenario-much like producing a counterfactual for the past where we recombine elements of a past event to consider how it could have happened differently (Schacter \& Addis, 2007; Suddendorf \& Corballis 1997; see Szpunar, 2010 for a review; counterfactuals see Byrne, 2002). "So...." Hermann contemplated "...looking inside the brain can also tell you how people use memory in other tasks, like thinking about the future?" "What on earth is next?"

We told him that these days we don't just look inside the brain, we can also tweak the processes in the brain that are crucial to memory. Advances in biotechnology have meant that we can look at ways to improve memory by targeting it at a biological level. One way to improve memory is to ask how we can remove unwanted memories. We suggested to Hermann that he was probably aware that when people experience horrible events, sometimes they remember them too well. We now know for instance, that when people remember trauma too well, they can experience Post Traumatic Stress Disorder (PTSD) where they are haunted by memories of a traumatic event via flashbacks, nightmares, and intense physical reactions such as elevated heart rate when they encounter 
reminders of the traumatic event (APA, 1994). These people wish they could forget and there might be a pill that can help them. There is growing evidence that giving people propranolol (a beta-blocker and "memory dampening drug") after a traumatic event can lead people to remember the trauma less intensely-it can dull the emotion associated with that memory-and reduce the incidence of PTSD (Brunet et al., 2008; Cahill, Prins, Weber, \& McGaugh, 1994; Pitman et al., 2002; Reist, Duffy, Fujimoto, \& Cahill, 2001; see also Schiller et al., 2010). “I don't know if I like this idea..." Hermann said...."should we be doing these things...what are the consequences of this so-called dampening of memory?"

Well we said, pundits, philosophers and legal scholars have asked the same question and pondered whether dampening negative memories would actually harm us (see Kolber, 2006). Indeed, the President's Council on Bioethics (2003) raised many concerns about memory dampening drugs. They cautioned that deleting or dulling memories would affect our sense of identity-our memories make us who we are (President's Council on Bioethics, 2003; see also Conway \& Pleydell-Pearce, 2000; James, 1890/1950; Neisser, 1988; Wilson \& Ross, 2003). In fact, Hermann, the general public of today may share your sentiments, we said. In one study people imagined experiencing a traumatic event and considered whether they would want to take a memory dampening drug to help guard against the risk of developing PTSD. Although people wanted the choice to take the drug, most said they would not take it themselves (Newman, Berkowitz, Nelson, Garry, \& Loftus, 2011). Legal scholars have also expressed concerns about deleting or dampening memory and raised important ethical issues-should a victim of a serious assault have the right to be free from traumatic memory, or do they have a societal obligation to remember the crime so that perpetrators can be identified later (Kolber, 2006)? This issue of memory dampening is one of many that comes up under the rubric of cosmetic neurology - the idea that we can craft the perfect brain, just like we can craft the perfect body through cosmetic surgery. There are drugs to dampen memory, but also ones to perfect it. If citizens start taking truly effective memory boosters or enhancers, perhaps to the point of having near perfect memories, what kind world would it be? "I don't want to live in that world. " Hermann said. "...what would be the fate for my forgetting curve."

\section{The Malleability of Memory}

Well, you know what Hermann, we responded. As much as these technologies would provide more fine grained control over what we remember, the brain is pretty good at editing events already. In fact, we are biased to remember aspects of our life as more positive and successful than they really were (see Ross \& Wilson, 2002). For example, people remember gaining better grades than they really did in high school (Bahrick, Hall, \& Berger, 1996; see also Gramzow \& Willard, 2006). "Why would people do this?" he wondered. We explained that it might be that remembering the past in a rosy way is actually pretty good for us, in fact we tend to do it when we think about the future too (D'Argembeau \& Van der Linden, 2006; Newby-Clark \& Ross, 2003; see also Szpunar, Addis, \& Schacter, 2012). As we mentioned earlier there is a strong link between memory and the self and rosy remembering of our own lives can serve to maintain a positive sense of self (e.g. Ross \& Wilson, 2002). Recalling the past in a negative way, a pattern observed with depressed individuals, might serve to do the opposite (Bradley, Mogg, \& Williams, 1995; Ridout, Astell, Reid, Glen, \& O'Caroll, 2003; for a review see Mineka \& Nugent 1995). That the brain edits our pasts in a positive light is healthy to the extent that it can promote a positive-though illusory-view of the self (see Ross \& Wilson, 2002; Newman \& Lindsay, 2009).

What we told Hermann next was even more surprising to him, namely, that when the human brain distorts memory in this way, these revisions often feel like a veridical version of the past. From our own experience we know that when we recollect the past it often brings with it a sense of being inserted back in time, as though we are 
re-experiencing that moment (Tulving, 1983, 2002). Although often full with perceptual information and details about who was present and what happened, our memory for the past is not a rigid retelling of prior experience. Rather, we have learned that memory is a story with a flexible narrative that can improve, sharpen and distort prior experience. We stressed to Hermann that to recall the past is vastly different from playing back a mental videotape. We have learned that people can have the experience of remembering a real event-what comes to mind shares all the features of a real memory - when what they remember is wrong, full of incorrect details, and at times even completely inaccurate.

For example, after learning about a shocking emotional public event like the death of a politician or the start of a war, people often have the subjective experience of remembering exactly where they were and what they were doing when they heard the news (Brown \& Kulik, 1977; Hirst et al., 2009; Neisser \& Harsch, 1992). But people are often wrong, initially reporting they first heard the news at school from a friend and later remembering that they first heard it at home while watching the television. Moreover, people believe their inaccurate memories and are surprised when they see their initial reports (Neisser \& Harsch, 1992; see Talarico \& Rubin, 2003). We also noted that memory can deceive us in even more dramatic ways; asking people to review old photographs or imagine childhood events can lead them to have rich, detailed filled memories for entire events that never occurred (Garry, Manning, Loftus, \& Sherman, 1996; Hyman \& Pentland, 1996; Lindsay, Hagen, Read, Wade, \& Garry, 2004; Loftus \& Pickrell, 1995). So we reiterated to Hermann that when we try to remember something, we reconstruct, rather than playback; The information that comes to mind it not always what we are trying to retrieve-it can be a mix of prior knowledge, information from a number of related events and ideas or thoughts we have had about the event since it occurred (for a review of false memory research see Garry \& Hayne, 2006; Loftus, 2003; Schacter, 2001). As noted in a recent book review covering the history of memory research: "The thing we feel sure makes us ourselves (no memory, no me) is also something we know to be treacherous, over-accommodating, fugitive: delightfully and fearfully unreliable." (Diski, 2012).

Although the brain can do a good job of editing without us detecting its revisions, there is also a category of revised memories that we know are completely false. Out of curiosity, we asked Hermann whether he had a memory that he knew was false. Some of us "remember" fairytale events such as Santa climbing down the chimney and some of us recall more realistic, but implausible childhood events such as feeding a family pet-that had died before we were born. People often do this, and sometimes it can be embarrassing. Mitt Romney, one of the 2012 candidates for the Republican nomination to the U.S Presidency described his memory of attending the Automotive Golden Jubilee, a large public event in June of 1946. The problem is Romney was born in March of 1947, so he couldn't possibly have been there (Potter, 2012, February 27). People have memories of all sorts of things that they know are completely false. In a recent study Mazzoni, Scoboria, and Harvey (2010) found that $20 \%$ of their subjects had a rich recollection of an event they knew never happened.

In fact these non-believed memories are so fascinating that they have become the subject of art. Hermann said "...well, artists have been intrigued by memory for a long time, but none knew of the perils that you describe." We told Hermann that Alasdair Hopwood and the WiTH Collective hope to depict these perils in their artwork. They have created a website for people to submit their non-believed false memories to display in an art exhibition. ${ }^{1}$ As of early 2012, Alasdair had collected over 300 non-believed memories, that range from remembering losing a shoe in a river to remembering a family pet being hit by a car. As flexible as the memory system can be, it might be pretty difficult to get rid of some memories. What do people do when they have a non-believed memory? If it is about remembering Santa they can entertain others with its implausibility. But what if that memory hurts the 
rememberer and it is about a more upsetting event? Then it might cause harm. We have talked about research investigating how we can remove memory for real negative events, but perhaps, people will start to consider whether we should also be contemplating the same for known false events? After all, there is evidence that distressing memories, true or false, can produce the same psychophysiological stress response (McNally et al., 2004).

"Well", Hermann said, "you have made some pretty astonishing advances in the science of memory. But some old ideas still seem to ring true. A fellow academic of my time, Friedrich Nietzsche once said that without forgetting, it is quite impossible to live at all (Nietzsche, 1980, p.10). Indeed, it seems that even in your day, forgetting might be one of the most important attributes of human memory, but then again, I am biased."

\section{Notes}

\section{1) http://falsememoryarchive.com/}

\section{References}

Addis, D. R., Wong, A. T., \& Schacter, D. L. (2007). Remembering the past and imagining the future: Common and distinct neural substrates during event construction and elaboration. Neuropsychologia, 45, 1363-1377. doi:10.1016/j.neuropsychologia.2006.10.016

American Psychiatric Association. (1994). Diagnostic and statistical manual of mental disorders (DSM-IV). Washington, DC: APA.

Bahrick, H. P., Hall, L. K., \& Berger, S. A. (1996). Accuracy and distortion in memory for high school grades. Psychological Science, 7, 265-271. doi:10.1111/j.1467-9280.1996.tb00372.x

Bradley, B. P., Mogg, K., \& Williams, R. (1995). Implicit and explicit memory for emotion-congruent information in clinical depression and anxiety. Behaviour Research and Therapy, 33, 755-770. doi:10.1016/0005-7967(95)00029-W

Brown, R., \& Kulik, J. (1977). Flashbulb memories. Cognition, 5, 73-99. doi:10.1016/0010-0277(77)90018-X

Brunet, A., Orr, S. P., Tremblay, J., Robertson, K., Nader, K., \& Pitman, R. K. (2008). Effect of post-retrieval propranolol on psychophysiologic responding during subsequent script-driven traumatic imagery in post-traumatic stress disorder. Journal of Psychiatric Research, 42, 503-506. doi:10.1016/j.jpsychires.2007.05.006

Byrne, R. M. J. (2002). Mental models and counterfactual thoughts about what might have been. Trends in Cognitive Sciences, 6, 426-431. doi:10.1016/S1364-6613(02)01974-5

Cabeza, R., \& St. Jacques, P. L. (2007). Functional neuroimaging of autobiographical memory. Trends in Cognitive Sciences, 11, 219-227. doi:10.1016/j.tics.2007.02.005

Cahill, L., Prins, B., Weber, M., \& McGaugh, J. L. (1994). Beta-adrenergic activation and memory for emotional events. Nature, 371, 702-704. doi:10.1038/371702a0

Conway, M. A., \& Pleydell-Pearce, C. W. (2000). The construction of autobiographical memories in the self-memory system. Psychological Review, 107, 261-288. doi:10.1037/0033-295X.107.2.261 
D'Argembeau, A., \& Van der Linden, M. (2006). Individual differences in the phenomenology of mental time travel: The effect of vivid visual imagery and emotion regulation strategies. Consciousness and Cognition, 15, 342-350. doi:10.1016/j.concog.2005.09.001

Diski, J. (2012). The me who knew it. (Review of Memory: Fragments of a Modern History). London Review of Books, 34, $12-13$.

Garry, M., \& Hayne, H. (2006). Do justice and let the sky fall: Elizabeth Loftus and her contributions to science, law, and academic freedom. Hillsdale, NJ: Lawrence Erlbaum Associates Publishers.

Garry, M., Manning, C. G., Loftus, E. F., \& Sherman, S. J. (1996). Imagination inflation: Imagining a childhood event inflates confidence that it occurred. Psychonomic Bulletin \& Review, 3, 208-214. doi:10.3758/BF03212420

Gramzow, R. H., \& Willard, G. (2006). Exaggerating current and past performance: Motivated self-enhancement versus reconstructive memory. Personality and Social Psychology Bulletin, 32, 1114-1125. doi:10.1177/0146167206288600

Hirst, W., Phelps, E. A., Buckner, R. L., Budson, A. E., Cuc, A., Gabrieli, J. D. E., Vaidya, C. J. (2009). Long-term retention of the terrorist attack of september 11: Flashbulb memories, event memories, and the factors that influence their retention. Journal of Experimental Psychology. General, 138(2), 161-176. doi:10.1037/a0015527

Hyman, I. E., Jr, \& Pentland, J. (1996). The role of mental imagery in the creation of false childhood memories. Journal of Memory and Language, 35(2), 101-117. doi:10.1006/jmla.1996.0006

James, W. (1950). Principles of psychology. New York: Dover (Original work published in 1890)

Kolber, A. J. (2006). Therapeutic forgetting: The legal and ethical implications of memory dampening. Vanderbilt Law Review, $59,1561-1626$.

Lindsay, D. S., Hagen, L., Read, J. D., Wade, K. A., \& Garry, M. (2004). True photographs and false memories. Psychological Science, 15(3), 149-154. doi:10.1111/j.0956-7976.2004.01503002.x

Loftus, E. F. (2003). Make-believe memories. The American Psychologist, 58, 867-873. doi:10.1037/0003-066X.58.11.867

Loftus, E. F., \& Pickrell, J. E. (1995). The formation of false memories. Psychiatric Annals, 25, 720-725.

Mazzoni, G., Scoboria, A., \& Harvey, L. (2010). Non-believed memories. Psychological Science, 21(9), 1334-1340. doi:10.1177/0956797610379865

McNally, R. J., Lasko, N. B., Clancy, S. A., Macklin, M. L., Pitman, R. K., \& Orr, S. P. (2004). Psychophysiological responding during script-driven imagery in people reporting abduction by space aliens. Psychological Science, 15, $493-497$. doi:10.1111/j.0956-7976.2004.00707.x

Mineka, S., \& Nugent, K. (1995). Mood-congruent memory biases in anxiety and depression. In D. L. Schacter (Ed.), Memory distortions: How minds, brains, and societies reconstruct the past (pp. 173-193). Cambridge: Harvard University Press.

Neisser, U. (1988). Five kinds of self-knowledge. Philosophical Psychology, 1, 35-59. doi:10.1080/09515088808572924

Neisser, U., \& Harsch, N. (1992). Phantom flashbulbs: False recollections of hearing news about Challenger. In E. Winograd and U. Neisser (Eds.). Affect and accuracy in recall: Studies of "flashbulb memories," (pp. 9-31). Cambridge: Cambridge University Press. 
Newby-Clark, I. R., \& Ross, M. (2003). Conceiving the past and future. Personality and Social Psychology Bulletin, $29,807-818$. doi:10.1177/0146167203029007001

Newman, E. J., Berkowitz, S. R., Nelson, K. J., Garry, M., \& Loftus, E. F. (2011). Attitudes about memory dampening drugs depend on context and country. Applied Cognitive Psychology, 25, 675-681. doi:10.1002/acp.1740

Newman, E. J., \& Lindsay, D. S. (2009). False memories: What the hell are they for? Applied Cognitive Psychology, 23, 1105-1121. doi:10.1002/acp.1613

Nietzsche, F. (1980). On the advantage and disadvantage of history for life (P. Preuss, Trans.). Indianapolis: Hackett. (Original work published 1874)

Pitman, R. K., Sanders, K. M., Zusman, R. M., Healy, A. R., Cheema, F., Lasko, N. B., Orr, S. P. (2002). Pilot study of secondary prevention of posttraumatic stress disorder with propranolol. Biological Psychiatry, 51, 189-192.

doi:10.1016/S0006-3223(01)01279-3

Potter, M. (2012, February, 27). Mitt Romney couldn't have remembered Detroit milestone: he wasn't born. TheStar.com. Retrieved from http://www.thestar.com/news

President's Council on Bioethics. (2003). Beyond therapy: Biotechnology and the pursuit of happiness. Washington, DC: Government Printing Office.

Reist, C., Duffy, J. G., Fujimoto, K., \& Cahill, L. (2001). Beta-adrenergic blockade and emotional memory in PTSD. The International Journal of Neuropsychopharmacology, 4, 377-383. doi:10.1017/S1461145701002607

Ridout, N., Astell, A. J., Reid, I. C., Glen, T., \& O'Caroll, R. E. (2003). Memory bias for emotional facial expressions in major depression. Cognition and Emotion, 17, 101-122. doi:10.1080/02699930302272

Ross, M., \& Wilson, A. E. (2002). It feels like yesterday: Self-esteem, valence of personal past experiences, and judgments of subjective distance. Journal of Personality and Social Psychology, 82, 792-803. doi:10.1037/0022-3514.82.5.792

Schacter, D. L. (2001). The seven sins of memory: How the mind forgets and remembers. Boston, MA:Houghton, Mifflin and Company.

Schacter, D. L., \& Addis, D. R. (2007). The cognitive neuroscience of constructive memory: Remembering the past and imagining the future. Philosophical Transactions of the Royal Society of London, Series B, Biological Sciences, 362 , 773-786. doi:10.1098/rstb.2007.2087

Schiller, D., Monfils, M. H., Raio, C. M., Johnson, D. C., LeDoux, J. E., \& Phelps, E. A. (2010). Preventing the return of fear in humans using reconsolidation update methods. Nature, 463, 49-53. doi:10.1038/nature08637

Suddendorf, T., \& Corballis, M. C. (1997). Mental time travel and the evolution of the human mind. Genetic, Social, and General Psychology Monographs, 123, 133-167.

Suddendorf, T., \& Corballis, M. C. (2007). The evolution of foresight: What is mental time travel, and is it unique to humans? The Behavioral and Brain Sciences, 30, 299-313. doi:10.1017/S0140525X07001975

Szpunar, K. K. (2010). Episodic future thought: An emerging concept. Perspectives on Psychological Science, 5, $142-162$. doi:10.1177/1745691610362350

Europe's Journal of Psychology 
Szpunar, K. K., Addis, D. R., \& Schacter, D. L. (2012). Memory for emotional simulations: Remembering a rosy future.

Psychological Science, 23, 24-29. doi:10.1177/0956797611422237

Szpunar, K. K., Watson, J. M., \& McDermott, K. B. (2007). Neural substrates of envisioning the future. Proceedings of the National Academy of Sciences of the United States of America, 104, 642-647. doi:10.1073/pnas.0610082104

Talarico, J. M., \& Rubin, D. C. (2003). Confidence, not consistency, characterizes flashbulb memories. Psychological Science, 14, 455-461. doi:10.1111/1467-9280.02453

Tulving, E. (1983). Elements of episodic memory (Vol. 2). New York, NY: Oxford University Press.

Tulving, E. (2002). Episodic memory: From mind to brain. Annual Review of Psychology, 53, 1-25.

doi:10.1146/annurev.psych.53.100901.135114

Wilson, A. E., \& Ross, M. (2003). The identity function of autobiographical memory: Time is on our side. Memory (Hove,

England), 11, 137-149. doi:10.1080/741938210

\section{About the Authors}

Elizabeth Loftus is Distinguished Professor at the University of California - Irvine. She holds faculty positions in three departments (Psychology \& Social Behavior; Criminology, Law \& Society; and Cognitive Sciences), and in the School of Law. She has authored several hundred articles on the malleability of human memory, published 22 books and has been honoured with six honorary doctorates and election to the Royal Society of Edinburgh, the American Philosophical Society, and the National Academy of Sciences. She is past president of the Association for Psychological Science, the Western Psychological Association, and the American Psychology-Law Society.

Eryn Newman is a graduate student at Victoria University in Wellington, New Zealand. She is currently visiting the University of California, Irvine as Fulbright Scholar. 